\title{
EL CORSARISME MALLORQUÍ A LA MEDITERRÀNIA OCCIDENTAL. 1652-1698: UN COMERÇ FORÇAT
}

\author{
Por \\ ANGEL POVEDA I SANCHEZ
}

Després d'haver publicat diversos treballs sobre aspectes parcials del corsarisme - com són, per exemple, els que afecten la intervenció dels mallorquins en la Guerra del Segadors (1), questions administratives i jurídiques (2) i les dificultats que envolten l'estudi del cors berberesc (3) - i d'haver fet un primer estudi, inèdit, i que constituí la seva mèmoria de licenciatura (4), G. López Nadal presenta en la seua tesi doctoral un ample estudi sobre les relacions del cors mallorquí $i$ les societats riberenques de la Mediterrània Occidental durant la segona mitat del segle XVII. L'autor introdueix el present treball com l'examen especific d'una de les tres perspectives sota les quals deu realitzar-se el que considera un ambicios projecte: la història del cors mallorquí durant l'edat moderna. Els altres dos estadis són així mateix exposats en el capitol introductori, fent uns primers plantejaments sobre les línies directrius que $s$ 'han de seguir en les posteriors recerques. Les dues perspectives restants afectaran les relacions d'aquest cors amb: a) la societat que el genera: Mallorca, i b) l'estat on s'ampara: la monarquia hispana. En consequència, aquesta vegada s'analitza el cors mallorqui "afora de l'illa», examinant els seus moviments en virtut de les repercusions produides en aquelles societats que d'una manera o d'altra es veuen inel.ludiblement obligades a coneixer les depredacions dels seus mariners.

El treball es presenta amb una base documental tan ampla com dispersa. De fet, l'autor el reconeix quan assenyala que s'ha hagut de desplaçar als ports on els corsaris illencs s'havien fet sentir. L'ingent material arxivístic recollit -s'han consultat fons francesos, italians i espanyols - ve acompanyat d'una extensa i heterogénia historiografia on hi figuren juntament les obres més clàsi-

(1) "La participació del cors mallorqui a la desfeta de la revolta catalana (1637-1655), Bol.leti de la Societat Arqueológica Lul liana (Palma de Mallorca), 828-829, 1978, pp. 246-272; i uEls corsaris mallorquins i la Guerra dels segadors*, L'Avenç, núm. 23, Barcelona, 1980, pp. 46-51.

(2) *Competència entre el Consell d'Aragó i el Consell de Guerra pels judicis de les captures de cors a Mallorca: el cas de la presa "La Nueva Hierusalem" $(1677-1678)$, Fontes Rerum Balearium, III, Palma de Maliorca, 1979 . 1980, pp. 203-226.

(3) «Els enemigs de la Fe: un cas més de marginació històrican a Estudis de Prehistória, d'Hlistório de Mayurqa 1 d'Histdria de Mallorca, dedicats a Guillem Rosselló i Bordoy, Mallorca, 1982, pp. 281-301.

(4) El corsarisme mallorqur a la segona meitet del segle XVII: 1652-1682, Universitat Autònoma de Barcelona, 1978 (inèdita). 
ques - qualcuna d'interpretació certament obsoleta - amb les aportacions més recents dins el camp de la historiografia econòmica marítima.

La tesi es presenta dividida en tres parts, corresponents respectivament a les relacions amb França, el estats italians i Berberia. En les dues primeres, s'ha fet una segregació per capitols, segons sigui examinada una ruta comercial concreta - França - i un estat o port - Itàlia - La part referent a Berberia s'ofe reix contrariament com a tot un conjunt no fent altres separacions que les que impliquen un canvi temàtic important. Naturalment - i, de fet, l'autor insisteix en diferents ocasions - la interrelació entre les societats esmentades és quelcom a tenir sempre present per a fer entenedores les complexes articulacions succeildes en uns mateixos indrets i que corresponen, generalment, a l'area occidental de la Mediterrània.

En la primera part s'examina la interferència del cors mallarquí dins el tràfic comercial francés. A tals efects, López Nadal remarca els dos factors que possibiliten i determinen aquesta involucració: per una banda, l'existència, practicament in interrompuda, d'una situació conflictiva entre França i "Espanya" durant el perfode tractat; per una altra, la important xarxa comercial establerta entre els ports francesos, especialment el de Marsella, i els principals centres neuràlgics de l'economia mediterrània. La confluència d'aquests dos elements explica el ràpid procés de desenvolupament del cors illenc 0 , dit d'una altra manera, la seua extraordinària transformació, passant d'un estat "artesanal" a un altre de signe vertaderament empresarial. Així resulta que els mercants francesos esdevenen el principal objecte de captura pels depredadors maritims illencs. Les seves intervencions es succedeixen sobre cada una de les linies sostingudes pel comerç francés, ja sigui amb les de procedència ponentina, com és el cas de les aprehensions de les embarcacions bacalladeres - els «morutiers maloins" - atlàntics amb productes de l'Europa Meridional. El comerç, en definitiva, queda notòriament afectat; les captures són nombroses i els carregaments interceptats, especialment els procedents de Llevant, suposen pèrdues força considerables. López Nadal tracta detalladament tot el relacionat amb aquestes interferèncias, des de les relacions que afecten a les captures fins les reaccions que produeixen dins l'organisme encarregat de controlar la navegació francesa pel Mediterràni: la Chambre de Commerce de Marsella. S'examinen igualment els testimonis dels consols del Cristianíssim en els principals ports italians i els remeis que s'intenten posar per evitar aquestes intervencions. Dins el panorama general, crec que val la pena subratllar el darrer subcapítol on, analitzant minuciosament un registre dels arxius marsellesos, l'autor aconsegueix comptabilitzar el nombre de baixes sofertes pel comerç francés, degudes a depredacions corsàries i a accidents de signe natural com són els enfonsaments, els incendis, els naufragis, etc. El període registrat és, malauradament, força baix -14 anys,- 9 dels quals corresponen als de la Guerra de la Lliga d'Augsbourg (1688-1697). Durant aquest conflicte, segon es desprén del treball de López Nadal, els mallorquins es fan amb 54 embarcacions, dues menys que les atribuides als anglesos, nació que operava gairebé amb una organització profesional estatal. Hom pensa que la mera presència d'aquests corsaris al costat de la incipiente totpoderosa "Royal Navy" reflecteix l'insòlit abast adquirit per l'empresa corsària illenca.

A aquesta part, cap assenyalar una certa imprecisió a l'hora de mesurar quantitativament el potencial marítim francés enfrontat als corsaris.

En la segona part s'estudien els contactes amb els estats independents 
d'Italia. Prel.ludiant una major atenció en nous treballs, l'autor omite ix voluntariament l'estudi de les relacions amb Sardenya, Nàpols i Sicília, "regnes" integrats dins l'aparell administratiu de la monarquia católica. No obstant aixó, López Nadal es permet tractar sobre la importancia de Finale, estratègic enclau "espanyol" dins les riberes de la Liguria; en aquest sentit, es de preveure que les relacions amb aquest "petit" port, puguin ésser aplicades amb bona part a la resta de territoris dependents de la corona "espanyola". Centran-nos de plé en aquesta part, cal remarcar que l'autor dedica la majoria de les seves planes a les comunicacions amb Gènova i Livorno, a tesa llur neutralitat política i la seua diferent manera de rebre els impactes del cors illenc. Mentre el port ligur pateix les actuacions dels corsaris al llarg dels seus litorals, arriscant seriósament les seues relacions amb França, Livorno sap administrar més eficaçment la seua condició de port neutral, obtenint grans beneficis gràcies a les aportacions d'aquests corsaris. Si per Gènova, el corsarisme mallorquí i el corsarisme en general representa un factor que perjudica força la seua economia, pel port toscà ocorre precisament el contrari: corsaris i negociants actuen en simbiosi; els primers condueixen les seves preses, els segons les adquireixen. Nogensmenys, no són aquests dos els únics ports que conegueren l'activitat corsària mallorquina; en menor proporció, altres ciutats, des de les savoianes fins a la mateixa Venècia, es veurien afectades per la intromisió del cors illenc, concretament en els seus contactes amb les terres del enemigs polítics del rei catòlic - França-i, també, dels enemigs "de la Fe", com eren les repúbliques del nord d'África i la Porta Sublim.

Les relacions amb Berberia es presenten com a dificilment controlables. Tal situació es deguda a diversos factors, forçadament entrelligats i que parteixen de la peculiar consideració dels berberescs com a uenemigs de la Fe». Tal acepció implica irremeiablement una diferent manera d'ésser tractats en comparació amb els enemigs de la Corona, es a dir, els adversaris exclussivament polítics. En efecte, mentre les relacions - captures, combats... - amb els països europeus porten darrera tot un procés institucional -protestes, judicis, repressions...-. l'aprehensió de l'embarcació berberesca no pareix suposar cap tipus de problema: la captura está ben feta i prou. D'aquesta situació es despren una lógica reducció de material documental a examinar, perfectament reflectit en els fons arxivistics consultats. Un factor adicional és el de voler muntar aquest anàlisi sobre documentació estrictament europea, sense acudir a les fons propiament magrebines. Lluny de silenciar-ho, l'autor el fa constar, reconeixent el caire parcial, i per tant insuficient, que presenta aquesta part.

López Nadal, però no s'acovarda. Conscient d'aquestes importants limitacions, fonamentalment metodologiques, ofereix un llarg discurs, tractant de tot el que s'acosta al cors i esbrinant amb esforc una inmensa sèrie d'aspectes que, si bé no totalment marginals, sí presenten una dimensió autònoma respecte al procés corsari. Així, i després d'una curada i explicativa introducció, presenta quatre apartats on "grosso modo" fa l'examen d'aquests complexes contactes. Aquests apartats responen a:

A) El cors mallorquía Berberia, on s'estudia l'assistència d'aquests corsaris a les costes nordafricanes, explicada per motivassions de distint contingut, com són els polítics-militars - expedicions de càstig-, institucionals - ordenances de cors - , religioses - espirit de croada - i economiques - problema blader, etcètera.

B) Les captures, on es distingeix entre les preses fetes per terra, tal com 
acostumaven a fer els corsaris berberescs per les costes de l'arxipièlag balear, i les realitzades mar endins pels mateixos musulmans, pels mallorquins i pels eivissencs, fent comparacions al respecte.

C) $E / s$ pressoners, on s'analitza tot el relacionat amb la figura de l'esclau - "moro" - i del captiu - "cristia" - incident en les consequències económiques i socials que deparava l'absorció de l'element humà com a objecte prioritari entre les mercaderies capturades reciprocament entre aquests corsaris, i

D) El cors mallorquí i e/ cors berberesc, on es fa, encara que de manera un poc curta, una precisa anàlisi sobre les interconexions entre aquest dos tipus de corsarisme, determinant el paper recíproc en llur procés de desenrrollament i els seus paradoxals efectes: nodriment del cors illenc i pèrdua de la capacitat operativa del cors berberesc musulmà .

La segona part de l'encapçalament de la tesi: "un comerc forçat", sintetitza les conclusions del treball. Dins la doble concepció sota la qual han d'interpretar-se aquestes tres paraules en el cas del cors mallorquí: 1) en tant que cors, i 2) pel que es deriva de la seua pràctica. L'autor es concentra en el darrer aspecte, deixant el primer per explicar-ho en nous treballs. En aquest sentit, el comerç forçat respon aixi a dues situacions les quals, encara que paral.leles, no deixen de mantenir una certa relació de causa-efecte. En primer lloc, la distorsió d'un comerc, digem-ne upacífic», regular, tal qual succedeix principalment en el sistema comercial francés on les escomeses dels mallorquins i dels corsaris que operaven contra els seus mercants, així com les intimidacions que produien llur mera presència, amenaçaven en col. lapsar bona part del trànsit en les seues rutes cap - o des dé- els diferents ports de la Mediterrània; el remei era necessari pero resultava extremadament car ja pel que implicava la defensa dels litorals per on traficaven els seus mercants - guardacostes, aplicació de la marina reial...-. ja pel que suposava poder garantir las transaccions marítmes-escortaments, combois...-. En segón lloc, la configuració del que s'ha anomenat comerc dels neutrals, recurs al que acudien les societats afectades, tot i confiant que el pabelló garantís les operacions comercials que es pretenien dur a terme. Aquest procediment seria, en un principi, el més emprat pels francesos, al mateix temps que significava per les nacions neutrals una esplèndida avinentesa per l'expansió dels seus negocis. Aviat, però, els corsaris s'en adonen de l'estratagema; llavors, desconfiant de tota bandera, in tervindrien sobre una embarcació i un altra. Les consequències són fàcils d'imaginar: el comerç de les nacions neutrals, augmentat per les guerres, esdevindria víctima d'elles; els corsaris el creen i els corsaris el destrueixen. I els mallorquins no escapen a la regla general. El paràgraf final es prou aclaridor: "Els efectes són, doncs, prou clars: mentre uns ports, els mes, veuen com perden moltes de les seues embarcacions - Marsella, Martigues, Gènova, Alger...-, d'altres, els menys, s'enriqueixen amb el comerç forçat dels mallorquins. Aquells vaixells, francesos, per exemple, que havien sortit cap a Livorno, hi arribaven finalment conduits, però, pels corsaris mallorquins. El comerç havia canviat violentament de mans".

La tesi fou presentada el dia 10 de setembre a la Facultat de Lletres de la Universitat Autònoma de Barcelona, defensant-la davant un tribunal format pels seguents profesors: Ricardo García Cárcel, president; Josep Fontana, Jaume Torras, Alberto Tenenti i Joaquim Nadal, ponents; éssent qualificada d'Excel.lent "Cum lauden. 
Aquest treball fou galardonat, la passada nit de Santa Llússia, amb el primer premi d'Investigació i Essaig Històric "Sant Jordi", convocat per primera vegada per la Federació del Congrés de Cultura Catalana. 